\title{
GROUNDING THE DREAM OF AFRICAN INNOVATION HUBS: TWO CASES IN KIGALI
}

\author{
NICOLAS FRIEDERICI \\ Humboldt Institute for Internet and Society \\ Französische Straße 9, 10117 Berlin, Germany \\ Oxford Internet Institute, University of Oxford \\ 1 St Giles, 1 St Giles Oxford, Oxford OX1 3JS, United Kingdom \\ nicolas.friederici@oii.ox.ac.uk
}

Received March 2018

Revised May 2018

\begin{abstract}
Innovation hub organizations have become a fixture in African cities. Proponents of hubs commonly envision them to function as network infrastructures: hubs are conceived of as network intermediaries within entrepreneurial ecosystems, allowing for seamless collaboration between diverse actors. This paper grounds such visions and conceptualizations, presenting case studies of two hubs in Rwanda: kLab and The Office. It draws on interviews with 47 participants with a stake in technology entrepreneurship in Kigali, about half of them founders or CEOs of small technology startups. Ultimately, the case studies show that implementation realities of hubs are far removed from aspirational visions. Notably, the paper finds that facets of community (such as boundaries and cultures) need to be continually negotiated between hub leaders and entrepreneurs, resulting in
\end{abstract} tensions and tradeoffs.

Keywords: innovation hubs, intermediaries, entrepreneurial ecosystems, Rwanda, Africa

\section{Introduction}

Innovation hub organizations, or "hubs," have become a fixture in African cities (De Beer, Millar, Mwangi, Nzomo, \& Rutenberg, 2017; Jiménez \& Zheng, 2017; Littlewood $\&$ Kiyumbu, 2017). Following the emergence of iHub Nairobi as a role model hub for the continent (Hersman, 2012), hubs have been envisioned to function as transformative catalysts for Africa's nascent digital and knowledge economies (Gathege \& Moraa, 2013; Kelly \& Firestone, 2016). Thriving on such goodwill and aspirations, the number of hubs in Africa has grown to more than 400, according to one recent tally (Bayen \& Giuliani, 2018).

Specifically, hubs are expected to enable early-stage technology entrepreneurs to make connections with each other and with diverse hub-external actors, such as corporations, investors, or international guests. The 'hub' metaphor is based on notions of interpersonal connectivity; hubs are seen as central nodes in wider social structures, letting people interact who would not otherwise do so: 
As these spaces become the nerve centres for the tech community, they also become critical international touch-points for those seeking to engage in technology and business in Africa. They are the new points of exchange for long-term expatriates and short-term visitors looking to identify trends, find local talent, and catch the African wave of innovation. (Kalan, 2014)

Such visions have coalesced in a sanguine narrative about African hubs, which can be summarized as the network infrastructure expectation (Friederici, 2018). Inspired by potentials rather than observed realities, this vision has become expansive in scope and scale. Not only have hubs been pictured as effective creators of entrepreneurial networks in African cities, they have also been assumed to have impact on a massive continentwide and sector-spanning scale (Bayen \& Giuliani, 2018; Kelly \& Firestone, 2016; Sambuli \& Whitt, 2017).

Yet, grounded studies of the lived realities of grassroots entrepreneurs (incl. freelance software developers, designers, artists, and makers) in African hubs are missing. Beyond suspiciously unison positive media coverage, focusing on the concept of innovation hubs and their promise as network infrastructures (Friederici, 2018), not much is known about what actually happens in African hubs. Only two scholarly contributions discuss hubs: one uses a single case study in Zambia to understand hubs' potential role for social development (Jiménez \& Zheng, 2017), while another analyzes the ways in which hubs in Kenya function as intermediaries (Littlewood \& Kiyumbu, 2017). Meanwhile, self- or donor-funded reports (Gathege \& Moraa, 2013; GIZ, 2013; infoDev \& CAD, 2014; Sambuli \& Whitt, 2017) have dominated the discussion, despite some apparent biases and low methodological rigor.

This paper builds on these arguments, theorizing hubs as intermediaries meant to facilitate flows of entrepreneurial resources within Africa's entrepreneurial ecosystems (Howells, 2006; Littlewood \& Kiyumbu, 2017; Spigel \& Harrison, 2018). To ground this theoretical framework and the hopes and dreams for hubs that have been flaunted by development organizations and the media, the paper then presents two detailed hub case studies from Rwanda: kLab and The Office. The cases represent vivid and dense summaries mainly of interviews with 47 participants in Kigali (incl. 24 entrepreneurs), conducted in September 2014. Follow-up interviews for verification were conducted with 10 participants in early 2017.

Following short sections introducing a simple theoretical framework and case studies as a method, the paper provides background information on Kigali's technology entrepreneurship environment, followed by detailed case studies of kLab and The Office. The paper then highlights idiosyncrasies and similarities of the two hubs, presenting some implications that focus on a comparison of the realities that were reflected in the case study data with the network infrastructure vision of hubs as described in Friederici (2018).

\section{Theoretical Framework}


Practitioners have envisioned African innovation hubs to function as seamless network infrastructures (Friederici, 2018). The hope is for hubs to become connection points for a range of diverse individuals and organizations, allowing them to form partnerships, learn from each other, and exchange resources. Ultimately, by connecting actors with a stake in African technology innovation, hubs are thus imagined to form the foundation of 'knowledge economies,' 'digital economies,' or 'ecosystems:'

Across [Africa] new Silicon Savannahs are in the making and the components of a budding... ecosystem are emerging... iHub-like innovation centers are becoming a mainstay of the continent's progressing ICT infrastructure... these IT spaces are becoming central connect points for ideas, entrepreneurs, investment, and innovation across the continent. (Bright \& Hruby, 2015)

Not only do [hubs] act as physical infrastructure, providing access to power, pipes (internet), and space, but they also offer network infrastructure, or access to the human, financial and social capital... Our belief is that investing in these spaces will create an innovation infrastructure that will encourage the growth of Africa's knowledge economy. (AfriLabs, 2015)

These practitioner ideas connect to theory on innovation intermediation (Howells, 2006; Littlewood \& Kiyumbu, 2017) and networks in entrepreneurial ecosystems (Spigel \& Harrison, 2018). Howells (2006) defines an innovation intermediary very broadly, as "an organization or body that acts as an agent or broker in any aspect of the innovation process between two or more parties" (p. 720). He mentions several examples for intermediation such as the provision of information about collaborators, brokerage of transactions, mediation, and supporting firms when they try to identify advice or funding. At its core, the innovation intermediation framework makes the case that there are many organizations other than firms that matter in innovation processes, and that they affect processes in many different ways.

The practitioner notion of hubs as network infrastructure also connects to theory on entrepreneurial ecosystems, because it explicitly argues that hubs create or improve flows of resources to entrepreneurs. Building on a range of empirical studies showing the importance of multi-actor networks in ecosystems (e.g., Cohen, 2006; Motoyama \& Knowlton, 2017), Spigel and Harrison (2018, Spigel 2017) recently proposed a relational process perspective on ecosystem development. A key concept is the notion of entrepreneurial resources, defined as 'resources specific to the entrepreneurship process... rather than other types of industrial benefits found in clusters that accrue to firms of all sizes and ages' (Spigel, 2017, p. 52). Based on this understanding of resources, the relational process perspective posits that entrepreneurial ecosystems are

ongoing processes of the development and flow of entrepreneurial resources... The presence and circulation of these resources helps explain 
how ecosystems evolve and transform over time and allows us to distinguish between strong, well-functioning ecosystems and weaker, poorly-functioning ones. (Spigel \& Harrison, 2018, p. 152)

The key argument is that entrepreneurial ecosystems depend on resource endowments, but also on the internal configuration of those resources, as this affects whether earlystage, growth-oriented entrepreneurs rather than incumbents, rent seekers, or non-growth oriented businesses have access to them. Ecosystem quality and development thus depend on system's endowment of entrepreneurial resources ('sparse' vs. 'munificent') but also its network strength ('well-functioning' vs. 'poorly functioning'). Well-functioning ecosystems are defined as those 'with dense networks between entrepreneurs, investors, advisors, and other key actors... support[ing] the flow of resources within the ecosystem, making it easier for entrepreneurs to access them' (Spigel \& Harrison, 2018, p. 164).

Together, intermediation theory and the relational theory of ecosystem development represent a theoretical framework that captures the network infrastructure expectation towards African innovation hubs. Namely, the network infrastructure expectation implicitly suggests that African hubs are a promising new type of intermediary organization that can facilitate the development of African entrepreneurial ecosystems by making them 'better-functioning' (i.e., increase their network strength), such that entrepreneurial resources flow more easily and become more accessible to entrepreneurs.

\section{Method}

The goal of this paper is to ground the network infrastructure expectation of hubs, which is equivalent to testing a theorization of hubs as viable network intermediaries in Africa's entrepreneurial ecosystems. This paper presents vivid and dense case studies of two technology innovation hub organizations: klab and The Office. As a research method, case studies provide "thick descriptions" of a phenomenon as it was observed by the researcher or his/her informants (Geertz, 1973). Good case studies do not claim to be an objective account, instead acknowledging that the same reality is perceived differently by different actors. Accordingly, validity and reliability are ensured through principles of multivocality, face validity, transferability, and resonance (Bochner, 2000; Golafshani, 2003; Tracy, 2010).

Multivocality is particularly important for this paper: nascent technology entrepreneurs were identified as the actors engaging with hubs in the most direct way possible, and so interviews with entrepreneurs were the primary data source. The case studies will condense their perspective and abridge their interpretations only to the minimum necessary extent. In total, 47 participants with a stake in technology entrepreneurship in Kigali were interviewed, about half of whom were founders or CEOs of small technology startups (see Table 1). The interviews were conducted in September 2014. A second visit to Rwanda in January 2017 was used to conduct follow-up interviews with 10 selected hub stakeholders. Due to the much more limited scope of the 
second round of interviews, data collection did not enable a full-fledged longitudinal analysis. Instead, the interviews were used for post-hoc verification of the initial results.

\begin{tabular}{lcc} 
& Kigali & \% of total \\
\hline Early-stage founders, CEOs & 24 & $51 \%$ \\
\hline Co-founders, startup employees & 4 & $9 \%$ \\
\hline Hub managers (former and current) & 4 & $9 \%$ \\
\hline Hub board members & 4 & $9 \%$ \\
\hline Other intermediary ${ }^{*}$ manager, staff, specialists & 5 & $11 \%$ \\
\hline Other actors (bloggers, mentors, consultants, etc.) & 3 & $6 \%$ \\
\hline CEO/founder of established local technology venture & 3 & $6 \%$ \\
\hline Total & 47 & $100 \%$ \\
\hline
\end{tabular}

Note: Participants with multiple roles were categorized by their main role. Hub managers for Kigali include former hub managers.

* "Other intermediaries" were incubators, startup and prototyping competitions, and entrepreneurial training initiatives.

Table 1: Number of interview participants per actor group and city

Case studies are necessarily a filtered and partially reduced representation of raw qualitative data (Huberman \& Miles, 1983). To balance the somewhat conflicting demands of multivocality and data reduction, the paper provides a single coherent and largely chronological account for each hub case study, but draws directly from participants' perspectives in constructing it. Different data sources (e.g., interviews vs. online blog posts) were compared against each other to assure the accuracy of reports, especially with regard to the founding histories and implementation stages of hubs. Especially in instances of ambiguity and conflicting data, the case studies use quotes to further convey multivocality.

Thereby, the paper moves beyond the visions, conceptualizations, and definitions of hubs in the previous reports and accounts proposed by development organizations and media outlets, and instead describes concrete, on-the-ground realities and histories. Notably, cases will illustrate how hub leaders' visions were confronted with the realities of implementation, and also indicate failures (as perceived by participants). Moreover, case studies allow the researcher to maintain a robust contextual and historical grounding, especially in the study of phenomena with unclear boundaries (Miles \& Huberman, 1994; Yin, 2009). This will allow for an examination of the network infrastructure expectation towards hubs.

While the case studies do not follow the same rigid template, each follows a roughly chronological account. The cases thus highlight in particular (1) the founding processes for each hub, including who the funders, founders, and leaders of each hub were and what visions and goals they pursued; (2) the actions of hubs towards entrepreneurs, expressed, 
for instance, in outreach to entrepreneurs, service offerings and adaptations, and actions taken by hub leaders; (3) which local entrepreneurs were engaging with hubs and how; and (4) ongoing social interactions within and around hubs. To ensure anonymity of participants, fictional names are used for all organizations that played a role in hub histories, except for the names of hubs themselves. No individuals are named.

\section{Empirical Context: Technology Entrepreneurship in Kigali}

\subsection{Country Context}

Kigali is often mentioned as one of the cleanest and safest cities in Africa. The city is the cultural and economic center of Rwanda, having grown rapidly to a size of about one million inhabitants since it became capital at the time of the country's independence in 1962. The city is easy and safe to navigate by car or moto taxi; commutes between different parts of the city usually take 20 to 30 minutes (e.g., between kLab and The Office).

The Rwandan state follows a patrimonial developmental model, where the government directly affects and often controls economic life (Booth \& Golooba-Mutebi, 2012; Hasselskog, 2015). The country remains a low-income country, but the fast rise of its wealth and development levels following the genocide of 1994 has been widely noted (World Bank, 2015). Vision 2020, the country's overarching development strategy, sets the goal for Rwanda to achieve middle-income status by 2020, focusing explicitly on ICTs as an enabler of economic development. The nation's rise in the World Bank's Doing Business rankings (to $3^{\text {rd }}$ and $2^{\text {nd }}$ among African nations in 2013 and 2014 respectively) was noted as a particular success story of the government's reform program (IFC, 2013; Traoré, Gonzalez, Yedro, Lobet, \& Bailey, 2012). The government also provides business directly: interviewed entrepreneurs described how the ICT sector depends on tenders by the government, as private demand for technology products remained low. Expatriates are explicitly part of the vision: Rwanda instituted a renewable two-year visa for Entrepreneurs in Information Technology to encourage qualified Westerners to settle in Rwanda and launch ventures. Many international development agencies have their offices in Kigali, and the city offers foreigners better quality of life than many other African capitals.

The vision that Rwanda could become the "Singapore of Africa" has been encouraged, if not actively promoted, by President Kagame ("Africa's Singapore?," 2012; Caryl, 2015). The "Digital President" (Collins, 2013b) shows his support directly, for instance, hosting large policy events in Kigali such as the bi-annual Transform Africa conference.

Yet, both Rwandese and expatriate participants also expressed that Rwandans are typically shy, courteous, unable to think critically and independently, and unwilling to lead or take risks, which was seen to be at odds with Silicon Valley-style technology entrepreneurship. There were also concerns that the national conversation had 
romanticized the notion of entrepreneurship and diluted public awareness about the challenges that technology entrepreneurs still face.

Entrepreneurs mostly reported that the business case for Rwandan technology startups was still difficult, despite the country's great aspirations. Entrepreneurs described how they could not build on common ways of doing things when trying to market digital products. Instead, entrepreneurs had to learn within industries and markets which were themselves still immature.

\subsection{Support for Technology Entrepreneurship Beyond Hubs}

Many participants believed that a lack of skills was the most pressing challenge for technology entrepreneurship. The Kigali Institute of Science and Technology (KIST) has increased the country's number of advanced technology students, but several participants highlighted that graduates typically need additional mentoring and training to be able to create technology products.

The government also provided funding for Carnegie Mellon University (CMU) to open a graduate degree program for East African students in Kigali, which participants praised as a crucial element in Rwanda's efforts to improve the skills of its ICT workforce and entrepreneurs. Yet, at the time of fieldwork, only two cohorts of students had graduated from the Master's program, and it remained unclear how influential CMU would ultimately become.

In recent years, several support organizations have attempted to further strengthen the support available for technology entrepreneurs. Several innovation competitions have been run, which entrepreneurs have welcomed as a source of small-scale prize money. In 2012, Tech Youth Rwanda began to host informal gatherings around technology entrepreneurship topics in collaboration with the Rwandan Agency for Economic Development (RAED). These activities were meant to complement the National Technology Association, which is a section of the Rwanda Business Alliance (RBA), a traditional business association, working as an interface between the private sector and the government.

In addition to kLab and The Office as Kigali's two innovation hubs, informal groups such as Tech Women Rwanda (running their events at kLab) and Fab Founders Rwanda (running their events at The Office) have been launched. Edify (housed at The Office) and Inkomoko provide entrepreneurial training and mentorship services, while FinConnect (also housed at The Office) aims to link entrepreneurs to financiers, for instance, by hosting pitching competitions. In 2014, a mobile operator launched the LaunchIT incubator in the Kacyiru neighborhood near kLab. At the end of 2014, shortly after fieldwork, the first cohort of four startups was accepted, including Accelerate HR, a kLab success story. However, the mobile operator later canceled its support and closed the incubator in early 2016.

\section{Case Study: kLab}




\subsection{Founding Process and Original Vision}

kLab was supported by the Rwandan Agency for Economic Development (RAED), as the government's implementing agency, in the context of the third NICI plan, oriented towards the support of a home-grown software and content development sector. This led to a perception that kLab is a government-initiated hub; however, RAED was neither a driver in the founding process of the hub, nor did it get directly involved in its management.

Tech Youth Rwanda, KigaliHackers (an informal group of software developers), and Ubwenge (a social impact-oriented software development startup) had been organizing ad hoc, informal gatherings around software development and entrepreneurship already in 2011. While interviewed entrepreneurs who had been kLab members from its beginnings emphasized that these parties were the initiators of kLab, kLab's founding story was told slightly differently in public. In this telling, the head of Rwanda Business Alliance (RBA), an adviser to RBA affiliated with an international development agency, and a professor at the soon-to-launch Carnegie Mellon University (CMU) Rwanda independently had the idea to start a tech hub akin to iHub in Nairobi:

I knew about iHub in Nairobi and I thought it was kind of crazy that we don't have something like that here! (kLab founding board member)

All parties had a joint meeting in November 2011, becoming founding organizations of kLab. The initial General Manager became an additional founding board member, as did the managing director of ProICT, a presentation of Rwanda's software development industry. RAED provided a space in the building where the National Technology Association had its offices, located in Kigali's Kacyiru neighborhood, a business district. The association became the administrating body for kLab, recruiting a General Manager as kLab's only employed staff. The international development agency that the RBA adviser was affiliated to funded renovations and furniture. In total, there were ten founding board members.

Almost the entire space at the top floor of the building was made available for hotdesking, with large window fronts instead of exterior walls. While the design was kept fairly simple, a coffee bar and a foosball table were included to give the space a casual feel and encourage informal conversations.

kLab's vision was initially relatively broad, loosely following what the founders knew about iHub. The goal was for kLab to be a "pre-incubator"-a place where technology ideas are developed and brought to market before additional support is received from elsewhere:

This is supposed to be the creation space: coming here, you try and fail. [It is] for coming up with a product that doesn't work, then leave it, [and] move on... we also keep in mind that this is an innovation space; you are allowed to come up with a crazy idea. (One of kLab's managers) 
In addition, some of the founders emphasized that the hub would need to address Rwanda's skill gap, and so skill building became a second, equally relevant goal. An initial goal was to pre-incubate 30 technology innovations, ten per year, and to have 200 active members after one year of operation (Batambuze III, 2013).

In kLab's initial plan, board members were tasked to mobilize resources, backing, and external contacts for entrepreneurs. They were also meant to mentor entrepreneurs directly during weekly sessions. In addition, kLab set out to engage external mentors, for instance, from technology companies in Kigali or from CMU. The university was launched shortly after kLab, with a facility in close proximity to the hub.

Mentors were meant to be technical experts and experienced business people. Subject-matter experts from different sectors were envisioned to be included on a caseby-case basis. Sessions were to be offered depending on the availability of mentors, but generally follow a regular weekly schedule. Individual entrepreneurs were also envisioned to be matched to mentors who did not give weekly sessions but had been included in kLab's database. Additionally, kLab aimed to match entrepreneurs with investors.

In sum, kLab started out with a diverse but technology-oriented board, pursuing broad and ambitious visions, having formulated a specific, largely hierarchical collaboration model, based on the idea that technology entrepreneurs should learn from more experienced business and technology experts. The roles that entrepreneurs, themselves, would play were not considered in depth.

\subsection{First Phase: Few, Dedicated Entrepreneurs Use kLab, Forming a Community}

From its informal launch in May 2012 until the time of field studies in October 2014, kLab's development can be divided in two phases that largely correspond to the tenures of the first and second General Manager. During the first stage, kLab hosted Ubwenge and a handful of newly founded technology startups. kLab had an application process: interested entrepreneurs needed to have a team in place and pitch their idea before being allowed to use the space. kLab's board was responsible for approving the applications, giving applicants the status of 'tenant.' Teams were rarely turned down but the informal hurdle meant that non-tenant entrepreneurs rarely frequented the kLab space.

At any given point, about five to seven teams or ten to 40 individuals (CEO founders, co-founders, and startup staff) were present in the hub space, working on their startups or startup ideas. As planned, mentorship and training programs happened regularly (kLab Rwanda, 2013), and kLab tenants were trained by board members and external mentors. The Ubwenge team had a special role, as its team provided informal, ad hoc software development coaching to other hub members on a daily basis. kLab hosted guests, ran two hackathons, and there were occasional open days on weekends. Technology Women Rwanda, an informal group of female technologists, occasionally used kLab's space for meet-ups. 
Still, tenants and mentors mostly had kLab for themselves. Accordingly, the space was rarely used at full capacity and all tenants knew each other. Interested entrepreneurs who had not yet passed the application stage were welcome to use the space informally, but the hub manager kept check on attendance and, if necessary, asked non-tenants to develop a startup project or leave. The core group of 20 or so regular users started to selfidentify as the core community of kLab. At the end of this phase, 85 tenants and 21 mentors were registered as members (Collins, 2013a), falling far short of the original goal of 200 active members.

\subsection{Second Phase: kLab Opens Up, Gets Known, but Attracts the 'Wrong' Users}

Following kLab's first year of operation, disagreements arose among the board and the General Manager. The board considered kLab's initial setup as not inclusive and effective enough, and started to insist that the manager increase outreach and meet the targeted number of tenant registrations.

kLab's second phase started around September 2013, shortly before the hub's official launch. kLab's first General Manager had left, and with a new manager, more events and ad hoc activities such as hackathons and pitching competitions were held. For instance, the Ministry of Agriculture ran several hackathons at kLab, seeking mobile applications that could be used by Rwanda's farmers. Several interview participants proudly told the anecdote that the country's Minister of ICT once visited kLab after midnight for a hackathon. kLab also received increased media attention, typically in the context of stories about Rwanda's transformation since the genocide, including by Time, Forbes, Wired, and Slate Magazine (Hiebert, 2013; Linshi, 2015; Strauss, 2014). In a Washington Post article (Raghavan, 2014), the General Manager described kLab as a "mini Silicon Valley." kLab thus became a convenient focal point for media, development organizations, entrepreneurship support organizers, and government agencies looking to connect with technology entrepreneurs. Several board members argued in interviews that it was a success in and of itself that Rwanda "had been put on the map" of technology entrepreneurship.

During this phase, kLab's access regime also changed. While the application policy was formally kept in place, it ceased to be enforced. This meant that individuals (mainly freelancers, university students, and recent graduates) started to frequent the hub space at their discretion. With a looser access policy, registered membership indeed rose quickly to about 600 in October 2014 (Ntabgoba, 2014).

However, this rise in activity actually became counterproductive in the eyes of several tenants: they felt that kLab was becoming an Internet café, with many new participants who were not serious about being technology entrepreneurs. Several interviewees reported that it became impossible to personally know everyone using the space.

Some entrepreneurs who had been with kLab from the beginning felt that the board got increasingly detached from the daily workings of kLab, and that its decisions were not conducive to the interests of kLab's core community. These participants were weary 
of conflicts of interest: they felt that kLab was not working for its entire community anymore, and merely helped a selected few who had strong connections to particular board members. They also said they respected the current manager, but that they were still disappointed that he so easily gave in to pressure from the board to attain "numbers" instead of creating an environment for focused startup work. These participants saw kLab as beyond their control, and not as an organization that they, themselves, could shape. In other words, while the fast-increasing headcount at first seemed to be an unequivocal success for kLab, ultimately doubts arose as to whether it would actually strengthen the membership composition and translate into favorable social dynamics for tenant entrepreneurs.

Moreover, some interviewees mentioned that national and international media had a tendency to overly promote kLab's successes and that kLab had an incentive to feed these stories, to the point where the increased attention had negative consequences. Such stories easily embedded kLab in the narrative of Rwanda's rise as an ICT nation, but some entrepreneurs feared that this outsize public image distracts kLab from its grassroots mandate.

In parallel, regular mentorship and training sessions ceased due to decreasing commitment of mentors and board members. Moreover, the two Ubwenge founders left Rwanda in 2014, which left other tenants with less opportunity to engage with highly skilled software developers during their daily work in the space. Tenants who had been with kLab for a longer time were informally given the status of 'senior tenants,' effectively assigning them the role of peer mentors. Other mentorship and coaching sessions were now held in a more ad-hoc fashion, based on tenants' individual relationships with a senior developer of Ubwenge that remained in-country, with CMU faculty, or with established technology entrepreneurs in Kigali. Some interview participants shared a sense that the original core community was dissipating irrespective of - or due to-much higher usage numbers, and that it became unclear if newcomers could replace or reinvigorate the community. Several participants said that they now started to see kLab as "just a space," and that they would stop using it once they could afford their own office space elsewhere in Kigali.

\subsection{State at the Time of Fieldwork: A Nested Social Structure and Many Intricate Balancing Acts}

At the time of fieldwork, virtually every early stage technology entrepreneur in Kigali had some sort of relationship with kLab. Yet, these relationships were extremely varied, differing in nature, intensity, and duration. Most technology entrepreneurs in Kigali either knew one of the board members, had worked at kLab for some time in the past, knew someone that worked in the space, or occasionally attended events and sessions. There also remained a (self-identified) core community at kLab; many interviewed members expressed a sense of like-mindedness and mutual respect towards other tenants, and most listed several friends and collaborators that they would meet and work with while in the space. Established entrepreneurs had established ties with kLab or its members; few 
kLab-affiliated startups had received investments and kLab had also become a place to easily access and recruit software developers. At the same time, not more than a handful of startups regularly using the kLab space had started to generate stable revenues.

kLab's leadership was now faced with a lot of uncertainty about the way forward. It began to realize some of the concerns about lacking member commitment. kLab had experienced that small changes in its access policy and service offerings could fundamentally affect its social environment, and that membership numbers alone were not indicative of collaboration. Concerns were now to define exactly who the stakeholders of kLab were, what its more concrete goals should be, and if and how the hub's governance structure should be altered.

Participants, from board members to tenants, had a common broad vision for an ideal $\mathrm{kLab}$, describing it as an organization or a place that instills skills and facilitates marketoriented, scalable innovations, but it appeared that 'the devil was in the detail.' For example, many entrepreneurs demanded more hands-on, one-on-one mentorship and active community management, while others said that the onus to change the hub's direction was on members themselves. For some participants, elements in Rwandan culture exacerbated the problems, because the entrepreneurs' humility and shyness meant that they would not take a more activist role in shaping kLab. Ultimately, several members acknowledged their responsibility and advocated regular plenary feedback sessions and greater representation on the board.

Responding to these challenges, kLab was about to emerge on a third phase at the time of field studies. In early October 2014, a third General Manager took over. The new manager initiated revisions of the membership process as a reaction to tenants' complaints. The vision was now to implement a formalized tier system, where more senior and focused members have privileged access to resources, while newcomers' time would be restricted.

\section{Case Study: The Office}

\subsection{Founding Process and Original Vision}

The Office in many ways followed a different model from kLab. It was started as a rentbased, privately run coworking space in late 2012. It was founded and owned by a USAmerican immigrant who had been a consultant in international development, moving to Rwanda in 2007 for an assignment with the Rwandan government. Between 2009 and 2012, he was based in London, where he heard from friends about coworking, without actually using a coworking space himself. Returning to Rwanda in 2012 for more consulting work, he envisioned starting an agro-processing company.

The impetus to launch The Office came then, out of his personal experience: when he was working from of a friend's home in Kigali, he felt that he would benefit from having access to a coworking space where he could meet likeminded others and share contacts for typical small business needs, such as setting up a website or finding 
suppliers. In particular, he believed that there were many "creative silos" in Kigali while a gathering place was missing. His understanding of "entrepreneurs" was broad and included small business owners, freelancers, artists, and "creatives."

In May 2012, the founder further developed the idea with two members of FinConnect Rwanda (a small business financing network). They began a word-of-mouth campaign and ran focus groups to elicit entrepreneurs' specific needs and their willingness to pay: the founders were determined to fund the operation from rent and usage fees. At the same time, the campaign served to promote the idea:

We really wanted to get people thinking outside the box, what their office would look like, talking to them about how they felt about innovation community... just planting the seed about what it is we are doing. (The Office founder)

The outreach was irrespective of economic sectors and according to the motto 'everything entrepreneurship.' A focus on any particular sector (such as technology) was explicitly avoided; the space was meant to be used by entrepreneurs from fields as diverse as film, music, technology, agriculture, or manufacturing.

True to the driving founder's original ideas, The Office ultimately "wanted to create a space where innovative and creative people could come together and build something bigger than the sum of their individual parts" (Huwart, 2015). What this would mean in concrete terms was explicitly left open:

Essentially... our goal is serendipity... we don't impose any expectations on the people in the community. We want people to basically become fulfilled individuals... people to be happy, people to be sort of pushing themselves. Whether that's starting a business or whether that's like making a really cool piece of artwork that maybe doesn't sell but maybe it's something that they are really proud of. (The Office founder)

Spatial design played a particular role for The Office (George Pericles, 2013):

The other interesting thing about the space itself is how the space is designed, not just to encourage casual collisions... and that there [are] very many subtle things that we have done to the space to make it feel very different from a normal office space in Rwanda. I mean, we have cut all the burglar bars ${ }^{\mathrm{a}}$ off the walls ... to make you feel very open when you are sitting inside the space. (The Office founder)

\footnotetext{
a "Burglar bars" are sturdy metal grids installed in front of house windows to secure a building from forced entry. They are common across Africa and also in Rwanda.
} 


\subsection{Entrepreneurship Support Organizations Move in, as Coworking Works for Some but Not All Entrepreneurs}

The coworking space started with twelve members in October 2012 (Huwart, 2015) in a building in Kigali's wealthy Kiyovu neighborhood. The Office offered hot-desking space to individuals and organizations by daily to yearly intervals.

During the founder's outreach, he had convinced several organizations to permanently rent office space on the floors underneath the coworking space. Around the time that The Office opened, FinConnect, Edify (an entrepreneurship training organization), and Kuzirikana (a locally known social technology startup) moved in as long-term tenants. Each of these organizations would bring their own contacts and activities related to entrepreneurship, which was expected to create mutual benefits. This allowed The Office to take up the building as a whole and created a steady flow of rent revenue.

Regular events (weekly to monthly) were hosted on the building's rooftop. Events were diverse, including talks, innovation competitions, lectures, happy hours, and workshops, but also movie nights, small concerts, and parties.

One of the startups regularly housed at The Office was a software development company that was also a social enterprise. The founder and CEO had been a core part of Tech Youth Rwanda, organizing events with RAED in 2011. She considered kLab but ultimately chose The Office due to the promise of contacts and inspiration that it would bring:

I had been to iHub [in Nairobi], I saw that and I had seen our own experience where we needed to be in a place that would support us, not just a physical space... We... moved in here because what we wanted was a great work environment. It's not even affordable office space I would say... but it was that environment that would allow our team to really innovate.

She also advocates for the benefits of having organizations with a related mandate close by, going so far as to compare being in the building with being in Silicon Valley:

I had done research on why Silicon Valley is what it is, and yes, I would say that everything I read about [it] is quite true, in terms of availability of funding, the willingness to take chances, ... when [The Office founder] mentioned what he was trying to do, I just knew, "Yeah, this is perfect." [We have] affordable office space upstairs... We have [FinConnect] a company that helps link entrepreneurs to investors right over there, we have [Edify] an incubator and accelerator downstairs... We have a connection with investors because of those guys, I have clients because of people upstairs. 
Yet, other participants reported that The Office might work for some, but not for all entrepreneurs - especially not for those interested in technology, those without means to afford rent or usage fees, and those uncomfortable with the atmosphere. Several participants described The Office as dominated by white immigrants, while others said that there was actually a balance between locals and foreigners. A technology entrepreneur affiliated with kLab shared the missing sense of belonging she feels at The Office:

I'll go back to using the word "down-to-earth..." no matter your economic background or status, at kLab, anyone is welcome and you don't feel like anyone is judging you. So, I feel, at The Office, it's a different class of Rwandan or different class of people who can be able to afford [to] go there... [in] Rwanda [with its] economic disparities, you really do have a majority of the young people that... would probably [have] a bit of [a] complex then.

Yet, others argued that this was precisely what was commendable about The Office while kLab's open policy had resulted in a lack of "community:"

[The Office] is the best place to be. It's so overwhelming to be there... I did love the community there... Because they are so cheerful... They are so welcoming... there are lots of things going on there. Anything new in Rwanda starts from there. I think people are getting to know The Office a lot now... People are like, "Ah, okay. You are going to The Office?" "Yeah." They are like, "Wow, you are someone" ... The people who work from The Office already have a foothold in society, and mainly, those who work in kLab are just people from nowhere... At kLab, there are a lot of people coming and others are going out... [I'm not at kLab] because there are a lot of people in there and then for the team to keep up with everyone, it's just a lot of tasks, because [of] the strangers there. (Technology entrepreneur at The Office)

Finally, some technology entrepreneurs held that The Office does not work for them because, there, it was harder to socialize with fellow software developers:

I like kLab because I come here to meet programmers. Sometimes I don't even come here to write code. I come here because I know that I will go out to lunch with a bunch of people, and we will be cracking jokes that are really funny in our own world, you know? [Laughter] (Technology entrepreneur at kLab)

Ultimately, a limited number of technology entrepreneurs engaged with The Office consistently while many attended events and visited the space occasionally. Participants generally had divided opinions about the typical stage at which entrepreneurs were using The Office: some argued that advanced entrepreneurs who can afford the fees and know 
how to make use of The Office's diverse contacts tended to be better represented, while others reasoned that it is a place to start out and develop ideas.

\subsection{Expansion of Reach, Coordinating a Wide Range of Actors}

As The Office evolved, it increasingly emphasized its goal to have reach beyond its space, approaching the vision of being a network infrastructure. The founder felt that The Office should differentiate itself from other entrepreneurship support organizations, and avoid duplicating their efforts. He began to identify a potential "silo effect" of coworking itself, and thus underlined that The Office was meant to be an interconnection point in a wider "cohesive and collaborative ecosystem that is churning out world-changing people and innovations" (Coworking Africa, 2015), stretching out across Kigali and beyond:
And so [if we were to provide incubation] in a sense, instead of creating an ecosystem in the city that's innovative and creative, we will end up creating these silos... so what I am doing is I am building an institution that will never engage in the zero-sum game. So essentially we are never competing with anybody in the city for anything. We are providing office space and we are creating a space for people to come together and do whatever they want. We are creating a space where [Edify] can come in and leverage the rest of their community in the building, and leverage our entire network and then provide a service that's actually useful to our community as well.

Taking this idea further, the founder later started referring to The Office as a "hub of hubs" (Coworking Africa, 2015).

He also engaged in a broader conversation about hubs and entrepreneurship support in Africa. The Office wanted to "collaborate by example," increasing the rate of interactions between diverse actors.

\subsection{State at the Time of Fieldwork: A New Site for Technology Entrepreneurs}

At the time of fieldwork, The Office was about to launch a coworking outpost in the Kacyiru neighborhood, near kLab and in the same building as the upcoming incubator LaunchIT. For the founder of The Office, this was a good example of the organization's expanding mandate:

The way I expressed it was that, having one tech innovation space in Kigali is fantastic, having three is probably fantastic, but having twenty is not. At some point there is a fallacy of composition ... so rather than trying to build this separate ecosystem, this separate silo... we came up with an arrangement... we are trying to create this win-win relationships across the city and in so doing, we are... getting more and more macro with how we are approaching the ecosystem. 
The Office increasingly engaged with social enterprise circles, and continued its focus on art, music, and fashion. As one of the first African hubs, it became part of the Impact Hub network in 2015.

In sum, The Office largely kept a consistent focus on being a connection node between diverse entrepreneurial actors. Still, its emphasis shifted from an initial focus on coworking and resident small businesses towards being a "hub of hubs," using events to loosely interconnect and inspire a wide range of actors, mainly from the social entrepreneurship field and creative sectors.

\section{Discussion}

This paper explored two cases of African innovation hubs, kLab and The Office in Kigali, Rwanda. The cases described concrete, on-the-ground realities and histories, thereby allowing readers to look beneath the visions, conceptualizations, and definitions of hubs that had been discussed before (Friederici, 2018; Gathege \& Moraa, 2013; Kelly \& Firestone, 2016; Sambuli \& Whitt, 2017). Thereby, the paper applied extant theory about intermediaries in entrepreneurial ecosystems (Howells, 2006; Spigel \& Harrison, 2018) to the specific case of African cities, highlighting some context-specific dynamics. In the following, some careful abstractions about hubs as ecosystem intermediaries will be made, in order to derive tentative implications and a critique of prior visions.

Unsurprisingly, the case studies showed that, once hub implementations began, leaders realized that they needed to adapt their vision to local conditions. However, the case studies also showed that this process of adaptation was particular to hubs: the issues that arose resulted specifically from tensions between aspirational hub visions and thorny hub realities.

Notably, both cases illustrated how hub leaders' initial visions were reminiscent of the network infrastructure expectation (Friederici, 2018), which assumes that hubs can be seamless integrators of wide networks of entrepreneurs, investors, development organizations, and others. Desirable notions of interpersonal and inter-organizational connectivity—such as 'community,' 'serendipity,' 'ecosystem,' 'openness,' 'exposure,' and the 'hub' metaphor itself-were essential in defining the aspirations of hub leaders and funders in both cases. Yet, soon after each hub was launched, the founders' network infrastructure expectations were confronted with the complicated and often conflicted realities of social interactions among entrepreneurs. Small and large failures (as perceived by participants) occurred, and leaders were confronted with an array of unforeseen yet significant organizational tradeoffs and tensions at the group or community level.

In sum, kLab started out with a diverse but technology-oriented board, pursuing a broad and ambitious vision that was inspired by iHub in Nairobi. Board members formulated a specific, largely hierarchical collaboration model, based on the idea that technology entrepreneurs should learn from more experienced business and technology experts. During kLab's first phase, about 20 tenants and mentors began to self-identify as the core community of kLab, using the space mostly for themselves, while it was rarely used at capacity. During the second phase, kLab's access regime became more open, 
allowing freelancers and recent graduates to frequent the space at their discretion. However, this rise in activity actually became counterproductive: many participants felt that kLab was becoming akin to an Internet café. kLab's defining tradeoff thus consisted of a balancing act between inclusiveness on the one side and community strength and technical skill levels on the other.

For The Office, the case study highlighted a different set of community-level tensions. The Office began as a rent-based, privately run coworking space. It was founded and owned by a US-American expatriate who had been a consultant in international development. The Office offered work space to individuals and organizations for pay. Several foreign entrepreneurship support organizations permanently rented office space on the floors underneath the coworking space, each bringing their own contacts and activities. The Office itself focused on regular events, celebrating entrepreneurship. This setup resulted in two different but interrelated tensions. The founder's emphasis on financial self-sustainability led to a pricing model that excluded some Rwandan grassroots entrepreneurs from regular use of the coworking space, not allowing a close-knit core community of locals to form. In parallel, The Office's progressive white immigrant-influenced culture was admired by some and admonished by other Rwandans.

Both hubs were also confronted with tough choices when it came to goal setting. Both appeared to make only a very small direct contribution to any given startup's development and success. Interestingly, this was seen to be a problem at kLab but not at The Office. The kLab board felt it needed to move from the broad goal to emulate iHub towards a more consistent and specific mission of its own, making tough choices when translating ideals into services and membership regimes. Accordingly, board members of kLab were soon divided over priorities, and entrepreneurs often felt that the hub's vision was detached from their realities. Ultimately, kLab leaders and members felt that more "process" (i.e., more hands-on services) was the right way forward, even if this was equivalent to moving away from the openness that was a defining feature of hubs and a precondition of the network infrastructure expectation (Friederici, 2018). In The Office's case, the hub moved in the opposite direction, focusing on events to allow for more openended networking, as this was seen to be a cost-effective solution to have the greatest possible reach to locals.

These sets of tensions and tradeoffs illustrate four themes which represent proof points for theorizing hubs as intermediaries and for future hub implementations. First and foremost, for all hubs, "community" is probably their most important asset, because participants' subjective and emotive sense of derived value underlies hubs' development impacts (Jiménez \& Zheng, 2017). However, "community" will be negotiated and delineated differently by any given hub. In particular, community formation processes necessarily depend on including some and excluding other local entrepreneurs. Aspirational hub visions like the network infrastructure glance over such uncomfortable realities of social organizing, while tradeoffs are bound to come up in hub 
implementations, requiring hub leaders to make tough choices at the expense of some of their potential stakeholders.

Second, the case studies showed that community dynamics are interrelated with hubs' goals and targets. Tensions can arise, in particular, when hubs attempt to be, at the same time, inclusive (high number and diversity of participants) and selective (low number or small groups of participants working on dedicated technology projects). Moreover, community strength appears to depend on members' familiarity with one another, which can be at odds with goals of diversity and inclusiveness. Any given hub appears having to balance the influx of new and different members with the regularity of space usage by its core community.

Third, the cases showed how hubs develop an organizational culture and identity, resulting from overlaps in values, demographics, and interests of community members at a given point in time. Importantly, such a culture can be self-reinforcing: new potential members might not choose to join a hub community if they perceive the existing community not to resonate with their personal profile.

Fourth, hubs' initial purposes became intertwined with funders' and founders' personal visions, beyond the broad imaginary of hubs as network infrastructures. Hub leaders played an important role in continuously redefining and modifying the stated purpose of a hub, which in turn served as starting point for setting cultural and institutional frameworks at the hub. In kLab's case, hub funder and founder organizations formed a board, governing the hub and overseeing the actions of the managers. Hub outreach also depended on board members' pre-existing connections: kLab involved established local technology entrepreneurs in Kigali based on several board members' personal contacts, while The Office's founder started from his personal connections when populating office spaces. This, in turn, meant that The Office symbolized the 'internationally connected' hub to other actors in Kigali, and that kLab became associated with Rwandan grassroots entrepreneurs and the local technology elite.

For policymakers interested in funding hubs, the key lesson of this paper is that they require a basic level of awareness of more complex or 'messy' dynamics of intermediation in entrepreneurial ecosystems. A simplistic conceptualization of hubs as transformative network infrastructures is bound to lead to disappointment. Intermediation can never be expected to be a seamless, apolitical, and uncontested process (e.g., Klerkx \& Leeuwis, 2008). In African ecosystems, difficulties and tensions are compounded by the newness of the phenomenon and by resource and capacity constraints (cf., Armanios, Eesley, Li, \& Eisenhardt, 2017). Funding African innovation hubs can be a good investment, but only if the hubs in question can effectively negotiate tradeoffs and reconcile conflicting needs of different stakeholder groups.

\section{Conclusion}

Overall, the case studies in this paper showed that hub realities are far removed from aspirational hub visions, for several reasons. For one, hubs rely on intricate balancing acts, for example, concerning the openness of access or the focus on particular 
technologies. In particular, hubs are well-advised to focus on "community" as their organizational purpose, while they also need to acknowledge that communities can be exclusionary and difficult to understand and define for different stakeholder groups.

Moreover, hubs develop a particular culture that depends in large part on founders' imprint, which can be at odds with ideals of envisioned stakeholder groups. The cases demonstrated the fluid decision making that hub funders and leaders (i.e., managers, staff, founders) engaged in, and how their decision-making was affected by evolving perceptions of purposes, successes, and failures of a given hub. At the same time, entrepreneurs also shaped hubs, mainly through their participation in or abstinence from events, and through the regularity with which they used hub spaces. This back and forth led to self-reinforcing community dynamics, and sometimes to homogenization of community membership rather than interconnection of diverse actors.

African hubs are now a pervasive but also a contested phenomenon. Case studies like the ones in this paper illustrate that hub practice needs to go beyond the hype and buzzwords, aiming to better understand opportunities and limits of hubs. As hubs continue to proliferate throughout Africa and other emerging markets (Bayen \& Giuliani, 2018; Seo-Zindy \& Heeks, 2017), it will be important to acknowledge that hubs are a unique organizational form with much promise especially for low-income contexts, but also that they face inherent tensions. Ultimately, for hubs to improve conditions for grassroots entrepreneurs, they need astute and farsighted leaders who can identify and defend the intricate balancing acts which community organization requires of them.

\section{References}

Africa's Singapore? (2012, February 25). The Economist. Retrieved from http://www.economist.com/node/21548263

AfriLabs. (2015). AfriLabs. Retrieved August 17, 2015, from http://afrilabs.com

Armanios, D. E., Eesley, C. E., Li, J., \& Eisenhardt, K. M. (2017). How entrepreneurs leverage institutional intermediaries in emerging economies to acquire public resources. Strategic Management Journal, 38(7), 1373-1390. https://doi.org/10.1002/smj.2575

Batambuze III, E. (2013, February 25). KLab, Rwanda's first innovation hub. Retrieved August 6, 2016, from http://pctechmag.com/2013/02/klab-rwandas-first-innovation-hub/

Bayen, M., \& Giuliani, D. (2018, March 20). 1000 Tech Hubs are Powering Ecosystems in Asia Pacific and Africa. Retrieved March 20, 2018, from https://www.gsma.com/mobilefordevelopment/programme/ecosystem-accelerator/1000tech-hubs-are-powering-ecosystems-in-asia-pacific-and-africa

Bochner, A. P. (2000). Criteria Against Ourselves. Qualitative Inquiry, 6(2), 266-272. https://doi.org/10.1177/107780040000600209

Booth, D., \& Golooba-Mutebi, F. (2012). Developmental patrimonialism? The case of Rwanda. African Affairs, 111(444), 379-403. https://doi.org/10.1093/afraf/ads026

Bright, J., \& Hruby, A. (2015, July 23). The Rise Of Silicon Savannah And Africa's Tech Movement. $\quad$ Retrieved $\quad$ October 28, 2015, from http://social.techcrunch.com/2015/07/23/the-rise-of-silicon-savannah-and-africas-techmovement/

Caryl, C. (2015, April 2). Africa's Singapore Dream. Retrieved August 4, 2016, from https://foreignpolicy.com/2015/04/02/africas-singapore-dream-rwanda-kagame-lee-kuanyew/ 
Cohen, B. (2006). Sustainable valley entrepreneurial ecosystems. Business Strategy and the Environment, 15(1), 1-14. https://doi.org/10.1002/bse.428

Collins, K. (2013a, October 30). Welcome to kLab, Rwanda's startup hub for top young tech talent. Retrieved October 22, 2015, from http://www.wired.co.uk/news/archive/2013-10/30/klab

Collins, K. (2013b, November 4). Exclusive: Rwanda's "digital president" Paul Kagame on technology's role in Africa's future. Retrieved August 5, 2016, from http://www.wired.co.uk/article/paul-kagame-exclusive-interview

Coworking Africa. (2015, March 23). Interview of Jon Stever, founder of The Office, Kigali (Rwanda). $\quad$ Retrieved $\quad$ October 23, 2015, from http://coworkingafrica.com/2015/03/25/interview-jon-stever-the-office-kigali/

De Beer, J., Millar, P., Mwangi, J., Nzomo, V. B., \& Rutenberg, I. (2017). A Framework for Assessing Technology Hubs in Africa. NYU Journal of Intellectual Property \& Entertainment Law, 6(2). Retrieved from http://jipel.law.nyu.edu/author/jeremydebeer/

Friederici, N. (2018). Hope and Hype in Africa's Digital Economy: The Rise of Innovation Hubs. In M. Graham (Ed.), Digital Economies at Global Margins. Boston, MA, USA: MIT Press.

Gathege, D., \& Moraa, H. (2013). Draft Report On Comparative Study On Innovation Hubs Across Africa. Nairobi: iHub Research. Retrieved from http://research.ihub.co.ke/uploads/2013/may/1367840837_923.pdf

Geertz, C. (1973). The interpretation of cultures: selected essays. New York: Basic Books.

George Pericles. (2013, December 8). The Office Rw - Interior. Retrieved October 23, 2015, from http://www.georgepericles.com/theoffice-rw/

GIZ. (2013). Technology Hubs--Creating space for change: Africa's technology innovation hubs. Deutsche Gesellschaft für Internationale Zusammenarbeit (GIZ) GmbH. Retrieved from http://10innovations.alumniportal.com/fileadmin/10innovations/dokumente/GIZ_10innov ations_Technology-Hubs_Brochure.pdf

Golafshani, N. (2003). Understanding Reliability and Validity in Qualitative Research. The Qualitative Report, 8(4), 597-606.

Hasselskog, M. (2015). Rwandan developmental 'social engineering': What does it imply and how is it displayed? Progress in Development Studies, 15(2), 154-169.

Hersman, E. (2012). Mobilizing Tech Entrepreneurs in Africa (Innovations Case Narrative: iHub). Innovations: Technology, Governance, Globalization, 7(4), 59-67. https://doi.org/10.1162/INOV_a_00152

Hiebert, P. (2013, December 18). High-Speed Recovery. Slate. Retrieved from http://www.slate.com/articles/technology/the_next_silicon_valley/2013/12/rwanda_s_hig h_tech_future_20_years_after_genocide_the_nation_aspires_to.html

Howells, J. (2006). Intermediation and the role of intermediaries in innovation. Research Policy, 35(5), 715-728. https://doi.org/10.1016/j.respol.2006.03.005

Huberman, A. M., \& Miles, M. B. (1983). Drawing valid meaning from qualitative data: Some techniques of data reduction and display. Quality and Quantity, 17(4), 281-339. https://doi.org/10.1007/BF00167541

Huwart, J.-Y. (2015). Jon Stever - The Office Kigali (Rwanda). Retrieved from https://www.youtube.com/watch?v=8WtcC4uQSfo

IFC. (2013, December 20). Leading the pack: Rwanda is Africa's best reformer in Doing Business 2014. Retrieved from http://www.ifc.org/wps/wcm/connect/region_ext_content/regions/subsaharan+africa/news/za_ifc_as_rwanda_doing_business_2014

infoDev, \& CAD. (2014). Do mLabs Make a Difference? A Holistic Outcome Assessment of infoDev's Mobile Entrepreneurship Enablers. Washington, DC: infoDev, The World Bank. Retrieved from http://www.infodev.org/mobile/mLaboutcomes

Jiménez, A., \& Zheng, Y. (2017). Tech hubs, innovation and development. Information Technology for Development, $O(0), 1-24$. https://doi.org/10.1080/02681102.2017.1335282 
Kalan, J. (2014, November 18). Inside East Africa's technology hubs. Retrieved July 16, 2016, from http://www.bbc.com/future/story/20121018-inside-africas-technology-hubs

Kelly, T., \& Firestone, R. (2016). How Tech Hubs are helping to Drive Economic Growth in Africa (Background Paper for the World Development Report 2016: Digital Dividends). Washington, DC: The World Bank. Retrieved from https://openknowledge.worldbank.org/bitstream/handle/10986/23645/WDR16-BP-HowTech-Hubs-are-helping-to-Drive-Economic-Growth-in-Africa-Kelly-Firestone.pdf

kLab Rwanda. (2013). kLab Official Launch. Retrieved from https://www.youtube.com/watch?v=dPwe9x4WTjo

Klerkx, L., \& Leeuwis, C. (2008). Balancing multiple interests: Embedding innovation intermediation in the agricultural knowledge infrastructure. Technovation, 28(6), 364378. https://doi.org/10.1016/j.technovation.2007.05.005

Linshi, J. (2015, April 7). Inside the Tech Revolution That Could Be Rwanda's Future. Time. Retrieved from http://time.com/3770968/rwanda-technology-genocide/

Littlewood, D. C., \& Kiyumbu, W. L. (2017). "Hub" organisations in Kenya: What are they? What do they do? And what is their potential? Technological Forecasting and Social Change. https://doi.org/10.1016/j.techfore.2017.09.031

Miles, M. B., \& Huberman, M. A. (1994). Qualitative data analysis: An expanded sourcebook (2nd ed., Vol. xiv). Thousand Oaks, CA, US: Sage Publications, Inc.

Motoyama, Y., \& Knowlton, K. (2017). Examining the Connections within the Startup Ecosystem: A Case Study of St. Louis. Entrepreneurship Research Journal, 7(1), 3-23. http://dx.doi.org/10.1515/erj-2016-0011

Ntabgoba, J. (2014, December 8). Did I fail both as a Startup Owner and a Tech Hub Manager? Retrieved October 22, 2015, from http://www.jiozlens.blogspot.jp/2014/12/did-i-failboth-as-startup-owner-and.html

Raghavan, S. (2014, April 4). Can a tech revolution prevent the envy and hatred that fueled Rwanda's genocide 20 years ago? Retrieved August 5, 2016, from https://www.washingtonpost.com/world/africa/20-years-after-the-genocide-rwandalooks-to-a-tech-revolution/2014/04/04/bbde2df2-bb4a-11e3-80de2ff8801f27af_story.html

Sambuli, N., \& Whitt, J. P. (2017). Technology innovation hubs and policy engagement. Brighton, UK: Institute of Development Studies. Retrieved from https://opendocs.ids.ac.uk/opendocs/handle/123456789/12860

Seo-Zindy, R., \& Heeks, R. (2017). Researching the Emergence of 3D Printing, Makerspaces, Hackerspaces and FabLabs in the Global South: A Scoping Review and Research Agenda on Digital Innovation and Fabrication Networks. The Electronic Journal of Information Systems in Developing Countries, 80(0). Retrieved from http://www.ejisdc.org/ojs2/index.php/ejisdc/article/view/1902

Spigel, B. (2017). The Relational Organization of Entrepreneurial Ecosystems. Entrepreneurship Theory and Practice, 41(1), 49-72. https://doi.org/10.1111/etap.12167

Spigel, B., \& Harrison, R. (2018). Toward a process theory of entrepreneurial ecosystems. Strategic Entrepreneurship Journal, 12(1), 151-168. https://doi.org/10.1002/sej.1268

Strauss, K. (2014, April 1). Let's Build A Tech Startup In ... Rwanda? Retrieved August 5, 2016, from http://www.forbes.com/sites/karstenstrauss/2014/04/01/lets-build-a-tech-startup-inrwanda/

Tracy, S. J. (2010). Qualitative Quality: Eight "Big-Tent" Criteria for Excellent Qualitative Research. Qualitative Inquiry, 16(10), 837-851. https://doi.org/10.1177/1077800410383121

Traoré, M., Gonzalez, A., Yedro, C. C., Lobet, J. M., \& Bailey, J. (2012). Rwanda: Fostering prosperity by promoting entrepreneurship (Doing Business). Washington, D.C.: World Bank. Retrieved

from http://www.doingbusiness.org/ /media/GIAWB/Doing\%20Business/Documents/AnnualReports/English/DB13-Chapters/DB13-CS-Rwanda.pdf 
World Bank. (2015, October 19). Rwanda Overview. Retrieved October 19, 2015, from http://www.worldbank.org/en/country/rwanda/overview

Yin, R. K. (2009). Case study research: Design and methods (4th ed.). Thousand Oaks: California Sage Publ. 